\title{
IMPACT OF ULTRA VIOLET IRRADIATION ON CRUDE FAT OF MALE AND FEMALE EXOSKELETON TISSUES IN HIGHER AGE GROUP.
}

\author{
Poonam Sherry \\ Former Lecturer (Chemistry), K. L. Mehta Dayanand College for Women, Faridabad \\ E-mail: poonmamsherrymathur@gmail.com
}

\begin{abstract}
Effect of UV irradiation in vitro was carried out in hair and nails samples of male and female residents of Faridabad district of Haryana. Biological samples of hair and nails were collected randomly from a higher age group (50 to 60 years) of different social status. The crude fat was extracted by Soxhlet Extractor using petroleum ether. The study showed the decreased concentration of crude fat which was approximately $2 \%$ in human hair and nails after exposure to UV for 1 hour. The reason for the decrease is the $\mathrm{C}-\mathrm{C}$ bond cleavage with the formation of free radicals and the evolution of ammonia. Exposure reduced the weight of the samples.
\end{abstract}

Keywords: crude fat, hair, nails, ultraviolet irradiation, petroleum ether

(C) RASĀYAN. All rights reserved

\section{INTRODUCTION}

The ozone layer shields the earth from harmful ultraviolet (UV) radiation which shows an adverse effect on photochemical and photobiological processes of human beings. The enhanced UV radiation is considered one of the global environmental problems which lead to various health issues for an individual. Radiation beyond the violet regions is called the ultraviolet radiation. The wavelength range of this region is from 4000 to $20 \AA \AA$. The radiations have high energy near ultraviolet region corresponding to $2000 \AA$ (frequency $1.5 \times 10^{15}$ ) has energy per Einstein equal to $1.43 \mathrm{X} 1015$ calories and UV (frequency $1.5 \times 10^{15}$ cycles for seconds) has energy $1.43 \times 107$ calories $^{1,2}$. The UV light is healthiest when it has a trace amount of ultraviolet. UV irradiation on the animal tissue brings degradation and aging. Enough evidence in this regard has been put forth by various research workers. UV irradiation causes progressive degradation in the collagen molecules in the smallest molecules fragments that subsequently lose their helical nature. The rate constants show that the denaturation of soluble collagen by UV irradiation is much slower than denaturation by heat or enzymes.

The determination of trace elements in hair has been the subject of continuous interest in the biomedical and environmental sciences ${ }^{3}$. Hair can be considered as an excretory product, the trace element contents of which reflect mineral metabolism in the body. However, their concentrations bear little relation to the levels in other tissues ${ }^{4}$. It should be noted that human hair is an attractive biological material because of the simplicity of sampling, transport and handling as well as providing information about concentrations of some trace elements that are considerably more concentrated in hair than other biological materials, which makes analysis easier ${ }^{5}$. Among many human tissues, hair and nails are widely used as biomarkers of the environmental burden of toxic metals due to ease of sample collection, transportation, storage, and preparation for analysis $6,7,8,9$. The importance of these examinations is attested by the fact that there are several trace elements in the human body that are important in biochemical processes ${ }^{10}$. Researches have been carried out with the aim of correlating various diseases ${ }^{11}$. An excess or absence of these essential trace elements causes serious problems in the physiology of the body ${ }^{12,13}$.

The effect of UV light on skin ${ }^{14}$ has been interpreted as causing aging in collagen through cross-linking within the collagen fibrils. Profiling the response of human hair follicles to ultraviolet radiation studied ${ }^{15}$.

Rasayan J. Chem., 12(1), 379-382(2019)

http://dx.doi.org/10.31788/RJC.2019.1211063

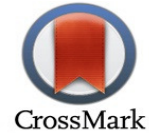


The negative effects of UV spectrum are that DNA (Deoxyribo Nucleic Acid)absorbs UV-B light and the absorbed energy can break bonds in the DNA. Most of the DNA breakages are repaired by proteins present in the cell nucleus but unrepaired genetic damage of the DNA can lead to even skin cancer. It also leads to genetic damage, cancer, aging, etc. Human hair \& nails are analyzed with the same analytical technique as biological samples for bio monitoring body burden of elements \& occupational exposure to metal pollution ${ }^{16,17,18,19}$. Exposure to toxic agents of organic elemental composition in human fingernails has been observed to that occupational use of harmful substances leads to decreased sulfur levels in the exposed persons, probably due to diminution of sulphur rich proteins in the nails, resulting from destruction of disulphide-bonds by alkaline and acid groups leads to damage of nail protein by harmful agents ${ }^{20}$. After 10 hours of UV irradiation, the moisture content of air-dried material in snake sloughs decreased extensively. But after 20 hours of UV exposure moisture content decreased with a higher percentage in fat contents due to free radical formation ${ }^{25}$.

Therefore, it is important to determine the organic constituents in humans to monitor and assess the UV impact on health. The organic constituent as crude fat in human exoskeleton (hair and nail) was determined in the higher age group (50-60 year). Effect of UV irradiation in vitro was carried out in samples of male and female residents of Faridabad, Haryana. The objective of this research paper is to make a humble effort in unfolding the manifold patterns of the chemical changes occurring after ultraviolet radiations.

\section{Material and Method}

\section{EXPERIMENTAL}

Samples were collected from the people working in offices, factories, roadside and residential area. Thirty samples in each category of male and female subjects were taken for the analysis. For subsequent analysis, each sample was sealed in plastic cover till it was washed, dried, digested and converted into solutions. Samples were washed thoroughly in separate beakers by several changes of distilling water and dried in air at room temperature for 36 hours. Samples of each group were taken together and grounded separately in an electrical grinder.

\section{General Procedure}

Moisture and Ash Content Analysis

Moisture was determined by keeping $1 \mathrm{~g}$ of air-dried material in an aluminum cup in an electric oven at $100^{\circ} \mathrm{c}$ for 24 hours and then weighing the oven dried material. Ash content was determined by keeping $1 \mathrm{~g}$ of the material in a muffle furnace at $900^{\circ} \mathrm{c}$ till the weight of the ash was constant.

\section{Analysis}

The concentration of crude fat was analyzed by using Soxhlet Extractor with petroleum ether $\left(40-60^{\circ} \mathrm{c}\right)$ for 6-8 hours. All the reagents used were of analytical grade procured from Merck (Germany) free from any metal contamination. A number of blanks were prepared for minimizing the contaminated errors. The main instrumental parameters of the UV lamp (like band width, lamp current, wave length, distance from the sample and 1-hour duration for irradiation) were maintained for estimation of crude fat before and after UV irradiation.

\section{RESULTS AND DISCUSSION}

An overall view of the results obtained the use of human exoskeleton as a diagnostic tool. A number of studies on a larger portion of the population will enhance the merit of such investigations and their applications in medical and forensic science. The value of crude fat investigated was significant after irradiation. Approximately $2 \%$ fall took place in crude fat after one hour of irradiation in hair and nail samples of male and female subjects. The reason for the decrease is the C-C bond cleavage with the formation of free radicals and the evolution of ammonia. Exposure reduced the weight of the samples.

As the wavelength is increased through the UV-A and UV-B regions damage to proteins becomes increasingly important because of the nucleic acids. In addition, many proteins that include the antioxidant enzymes catalases and peroxidases contain heme groups thus making them UV-A chromophores and potentially photosensitizers. Indeed, catalase is sensitive to sunlight ${ }^{21}$ probably as a result of UV-A absorption $^{22}$. In bacteria there is evidence that endogenous catalase and possibly alkyl hydroperoxide 
reductase are actually photosensitizers ${ }^{22,23}$. Repair enzymes are also sensitive to UV-A radiation and there is evidence that UV induced repair disruption plays a role in cell death and mutagenesis ${ }^{26}$. Considerable attention has been given recently to metal ion catalyzed oxidation of protein since that is clearly a physiologically relevant process ${ }^{24}$. Numerous proteins have been shown to be modified by a free radical generating, system modeling those that cells are exposed to during normal metabolism or exogenous insult. It appears that active oxygen / free radical species are generated at specific metal binding sites on proteins and that this leads to reaction with amino acids residues at specific steric locations. It is also deemed essential that certain preventive measures including protection from ultra violet radiation should be taken to safeguard the health of people.

Table-1: Crude Fat In Higher Age Group Before Irradiation

\begin{tabular}{c|c|c}
\hline Gender & Hair $(\mathrm{mg})$ & Nails $(\mathrm{mg})$ \\
\hline Male & 15.88 & 14.87 \\
\hline Female & 15.00 & 16.60 \\
\hline
\end{tabular}

Table-2: Crude Fat In Higher Age Group After Irradiation

\begin{tabular}{c|c|c}
\hline Gender & Hair $(\mathrm{mg})$ & Nails $(\mathrm{mg})$ \\
\hline Male & 15.56 & 14.57 \\
\hline Female & 14.7 & 16.00 \\
\hline
\end{tabular}

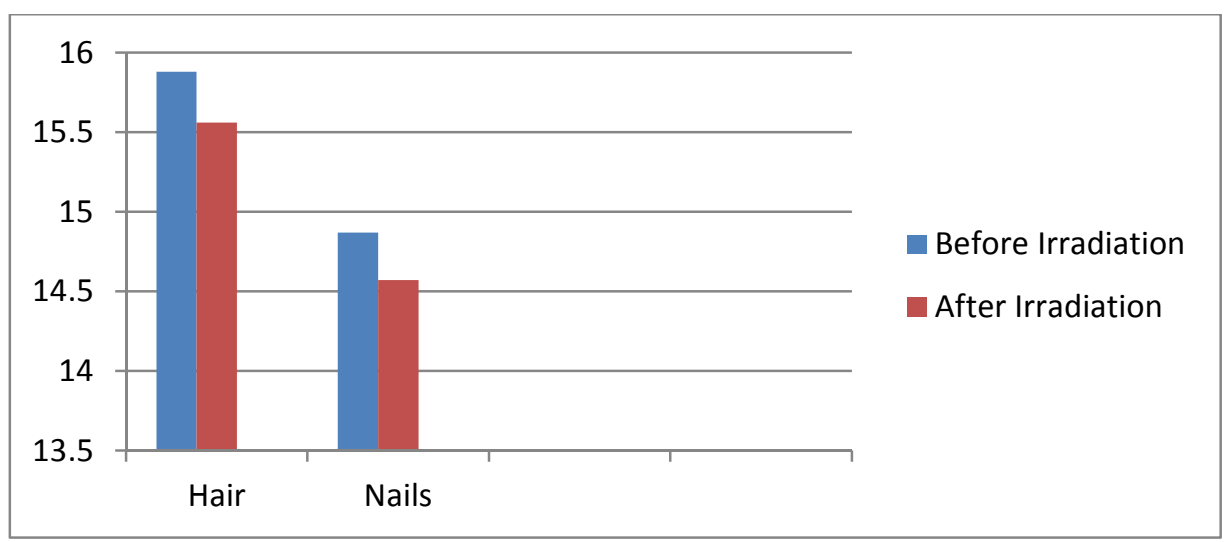

Fig.-1: Graphical Presentation of Crude Fat Pre and Post UV irradiation in Male Hair and Nails in Higher Age Group (values are expressed as mg.)

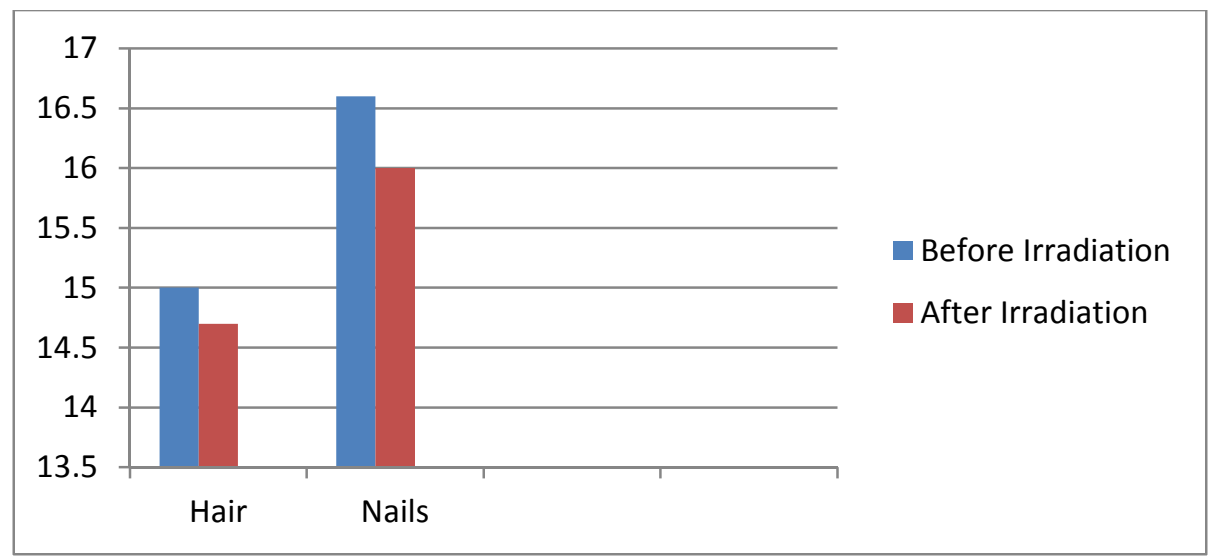

Fig.-2: Graphical Presentation of Crude Fat Pre and Post UV irradiation In Female Hair and Nails in Higher Age Group (values are expressed as mg.) 
RASĀYAN J. Chem.

Vol. 12 | No. 1 |379 - 382 | January - March | 2019

\section{CONCLUSION}

Human exoskeleton keratin comprising of major quantities of amino acids serine, cystine and glycine. The study shows that crude fat decreases in exoskeleton tissues after UV irradiation in vitro. Crude fat concentration decreased by $2 \%$ after 1 hour of UV irradiation. It is also deemed essential that certain preventive measures including protection from ultra violet radiation should be taken to safeguard the health of people.

\section{REFERENCES}

1. R. Gurdeep, Chhatwal, Photochemistry, Meerut Publishing House, India (1991)

2. Kemp, Organic Spectroscopy, Mc Millan Education, India (1986)

3. W. Arnold and H. Sachs, Journal of Analytical Chemistry, 348, 484 (1994)

4. J. Kałuza, M. Jeruszka and A. Brzozowska, Roczniki Panstwowego Zakladu Higieny, 52, 111(2001)

5. L. I. Zhuk and A.A. Kist, Journal of Radio analytical and Nuclear Chemistry, 195, 75 (1995)

6. B.Nowak, International Conference-Heavy Metals in the Environment, Toronto, 2, 408 (1993)

7. B. Agahian, J.S. Lee, J.H.., Nelson and R.E. Johns, American Industrial Hygiene Association Journal, 51, 646 (1990)

8. M. Schlegel-Zawadzka, Biological Trace Element Research, 32, 79 (1992)

9. D. Das et.al., Analyst, 120, 917 (1995)

10. F.I. Abdulrahman, J.C. Akan, Z.M, Chellube and M. Waziri, Borno State, Nigeria, World Environment, 2, 4, 81 (2012)

11. C. Y. Wang et.al, Micro Chemical Journal, 51, 5 (1995)

12. J. Dombovári and L. Papp, Microchemical Journal, 59, 187 (1998)

13. J. Dombovári, L. Papp, I. Uzonyi, I. Borbély-Kiss, Z. Elekes, Z. Varga, J. Matyus and G. Kakuk, Journal of Analytical Atomic Spectrometry, 14, 553 (1999).

14. E. Bottoms and S. Shuster, Nature, 199, 192 (1963)

15. Luz, T.W. Fischer, S. Hasse, K. Sugaware, Y. Kamenisch, S. Krengel, W. Funk, M. Berneburg and R. Paus, Journal of Investigative Dermatology, 129, 1790 (2009)

16. M. Wilhelm, I. Lombeck and F K. Ohnsesorge, Science of the Total Environment, 141, 275 (1994)

17. K.L.Chen and C.J. Amarasiriwardena, Biological Trace Elemental Research, 67I, 109 (1999)

18. G.M. Egeland, Ponce R., Knecht R., Bloom N.S., Fair J. and Middaugh J.P. , International Journal of Circumpolar Health, 58, 52 (1999)

19. H.K. Hira, K. Petal and K.S. Dhillion, Public Health Nutrition, 7, 39 (2004)

20. Elke Schumacher, Will Dindorf, and Manuela Dittmar, Science of The Total Environment, 407, 2151 (2009)

21. R. L. Mitchell and I.C. Anderson, Science, 150 74. (1965)

22. G.F. Kramer and B.N. Ames, Journal of. Bacteriology, 169, 2259 (1987)

23. A. Eisenstark and G Perrot, Molecular and General Genetics MGG, 207, 68 (1987)

24. E.R. Stadtman, Free Radical Biology and Medicine, 9, 315 (1990)

25. N. Chaturvedi. et al., International Journal of Engineering Technology Science \& Research, 4, 684 (2017)

26. R.B. Webb and R.M. Ty, 19, 361 (1973)

[RJC-1063/2013] 